\title{
Financial toxicity and employment status in cancer survivors. A systematic literature review
}

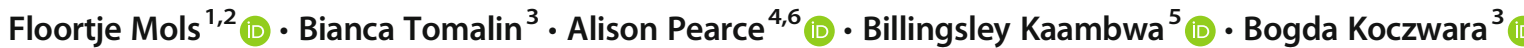

Received: 16 April 2020 / Accepted: 26 August 2020 / Published online: 31 August 2020

(C) The Author(s) 2020

\begin{abstract}
Background Financial toxicity has traditionally been attributed to the rising costs of cancer care. As ability to work impacts one's financial situation, limited employment and reduced income may also contribute to financial toxicity. We examined evidence of the association between financial toxicity and employment status in cancer survivors.

Methods A systematic literature review was performed via PubMed, Web of Science, CINAHL, and PsycINFO with search terms including "Cancer," "Financial toxicity," and "Employment" on September 25, 2019.

Results Thirty-one papers met eligibility criteria. Thirteen studies were rated as having high quality, 16 as adequate, and two as low. Being actively treated for cancer had serious negative consequences on employment and medical expenditures. Unemployment, changed or reduced employment, lost days at work, poor work ability, and changes to employment were associated with a higher risk of financial toxicity. Patients who were younger, non-white, unmarried, of low education, living with dependents, residing in non-metropolitan service areas, with lower income, and of low socioeconomic status were more at risk of financial toxicity. Other variables associated with financial toxicity included having a mortgage/personal loan, higher out of pocket costs and household bills, limited health insurance, more severely ill, on active treatment, and lower functioning or quality of life.
\end{abstract}

Conclusion Cancer negatively affects employment, and these changes are significant contributors to financial toxicity. Researchers, healthcare professionals, and patients themselves should all cooperate to tackle these complex issues.

Keywords Financial toxicity $\cdot$ Employment $\cdot$ Cancer survivors $\cdot$ Costs

\author{
Abbreviations \\ MeSH Medical Subject Heading \\ MM Multiple myeloma
}

Floortje Mols

F.Mols@tilburguniversity.edu

1 CoRPS - Center of Research on Psychological and Somatic Disorders, Department of Medical and Clinical Psychology, Tilburg University, Tilburg, The Netherlands

2 Department of Research, Netherlands Comprehensive Cancer Organisation (IKNL), Utrecht, The Netherlands

3 Flinders Centre for Innovation in Cancer (FCIC), Flinders Medical Centre and Flinders University, Adelaide, SA, Australia

4 Centre for Health Economics Research and Evaluations, University of Technology Sydney, Sydney, NSW, Australia

5 Health Economics, Flinders University, Adelaide, SA, Australia

6 Sydney School of Public Health, University of Sydney, Sydney, NSW, Australia

$\begin{array}{ll}\text { OOP } & \text { out-of-pocket } \\ \text { PRISMA } & \begin{array}{l}\text { Preferred Reporting Items for } \\ \text { Systematic Reviews and Meta-Analyses }\end{array} \\ \text { QOL } & \begin{array}{l}\text { Quality of life } \\ \text { (USA) }\end{array} \\ \text { United States of America }\end{array}$

\section{Introduction}

Financial toxicity refers to the financial burden or financial hardship experienced by cancer survivors because of cancer and its treatment $[1-3]$. The problem of financial toxicity is increasing since the costs of care are increasing with newer treatments, the prevalence of cancer is growing rapidly, and many survivors live with cancer as a chronic disease. Depending on the country and thus the healthcare system, financial toxicity prevalence varies widely, but studies have shown consistently that its presence is associated with lower 
quality of life, poorer adherence to or delay of care, and early mortality [4-7].

High costs of cancer care are a recognized cause of financial toxicity through medical costs (such as cost of new treatments), non-medical costs (e.g., travel costs to hospitals), or indirect costs (e.g., lost wages as a result of time off work for cancer treatment) [5]. Even if healthcare is available to everyone via universal health insurance coverage, patients have outof-pocket expenses (OOP) in relation to their disease and its treatment. Since many cancer survivors are known to experience long-term side effects and symptoms of cancer and its treatment, these costs can continue even years after diagnosis [8].

To date, a number of systematic reviews have examined financial toxicity in cancer survivors $[2,9,10]$. A recent review summarized 45 studies and concluded that $47-49 \%$ of cancer survivors reported some degree of financial distress [9]. Another recent review examined 25 studies from nine countries with the majority from the USA and showed that up to $73 \%$ of patients reported financial toxicity [2]. Predictors of financial toxicity included younger age, female gender, a more recent diagnosis, and use of adjuvant therapies [2]. A review that focused on the relationship between financial toxicity and symptom burden concluded that a clear association exists between financial toxicity and psychological symptoms like depression [10].

While the focus on financial toxicity has historically been on the costs of cancer care, especially in light of the significant rise in the cost of cancer medicine [11], limitations in or inability to work is also likely to contribute to financial toxicity $[2,9]$. Both income and changes in work participation have been associated with financial toxicity [2]. Similarly, reduced income and missed days of work due to illness are associated with financial hardship [9]. Data on employment after cancer show that as many as $40 \%$ of employed cancer survivors do not return to work after cancer diagnosis [12], and inability to work is associated with greater financial hardship and reduced quality of life [6]. Those more likely to return to work after diagnosis are individuals with a higher educational level, male gender, and younger age at diagnosis; those that underwent less invasive surgery, experienced fewer physical symptoms, and had a lower length of sick leave; and those with provision of workplace accommodations such as flexible hours or rehabilitation services, lower length of sick leave and continuity of care [13]. This significant overlap between predictors of financial toxicity and predictors of unemployment after cancer raises the question of how employment status and financial toxicity after cancer are related, taking into account a possibility of confounding.

To address this question, the primary aim of this systematic literature review was to examine the relationship between financial toxicity and employment in cancer survivors and any variables that may affect this relationship.

\section{Methods}

\section{Search strategy}

We followed the Preferred Reporting Items for Systematic Reviews and Meta-Analyses (PRISMA) guidelines [14]. A computerized search of the literature through the search engines PubMed, Web of Science, CINAHL, and PsycINFO was performed on September 25, 2019. The search terms captured concepts of "financial toxicity," "employment," and "cancer." Boolean operators and keywords were used with Medical Subject Headings (MeSH) where possible. Separate searches were conducted for each database. All search results were imported in EndNote, which was used to remove duplicates. Reference lists of all identified publications were checked to retrieve other relevant publications not identified by means of the computerized search.

\section{Inclusion and exclusion criteria}

Studies that met the following criteria were included: (1) if the objective was to describe financial toxicity and employment in adult cancer survivors, (2) if the publication described a quantitative study, (3) if the publication was an original article (e.g., no poster abstracts, editorials, reviews, and letters to the editor), (4) if they were published or in press in peerreview journals, and (5) if they were written in English. Studies were excluded for the following reasons: (1) if they included participants under the age of 18; (2) if they focused solely on spouses, caregivers, family of cancer survivors, or health professionals; or (3) if they included patients with other diseases besides cancer as well.

\section{Screening}

Articles were reviewed by title and abstract according to the pre-specified inclusion and exclusion criteria. Then full-text papers were reviewed to confirm eligibility. Results of the search were discussed, and any discrepancies were clarified until consensus was reached. A flowchart of this selection procedure is shown in Fig. 1.

\section{Quality assessment}

The methodological quality of all included articles was assessed according to predefined criteria using a 13-item standardized checklist. The checklist was a slightly adapted version of an established criteria list for systematic reviews $[15$, 16]. The criteria are presented in Table 1.

Each item of an article that matched our criteria received one point. Zero points were assigned if an item did not meet our criteria, was described insufficiently, or not at all. The highest possible score was 13 . Studies scoring $\geq 75 \%$ of the 
Fig. 1 PRISMA flow diagram

Table 1 List of criteria for assessing the methodological quality of studies on the association between financial toxicity and employment status
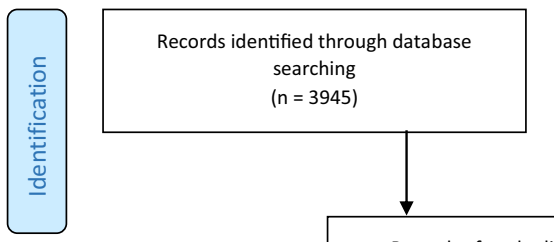

Records found through reference checking $(n=3945)$

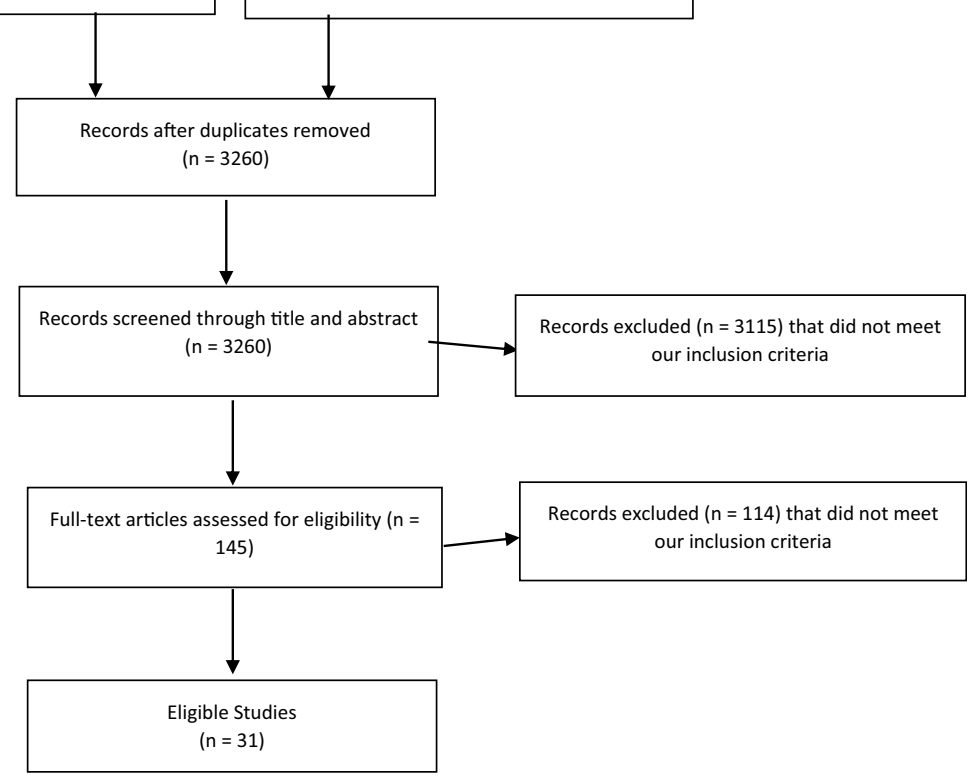

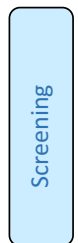
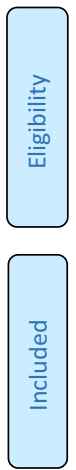

$$
(n=51)
$$$$
(n=31)
$$

\begin{tabular}{ll}
\hline Criteria & $\begin{array}{l}\text { Number of articles } \\
\text { meeting criteria } \\
(n=31)\end{array}$ \\
\hline
\end{tabular}

Positive if with respect to

Main outcomes

1 A validated financial toxicity questionnaire is used 11

2 Financial toxicity was assessed objectively 2

Study population

3 A description is included of at least two socio-demographic variables 31

4 A description is included of at least two clinical variables 30

$5 \quad$ Inclusion and/or exclusion criteria are described 28

6 Participation rates for patient groups are described and are $>70 \% \quad 10$

7 Information is given about the degree of selection of sample 9 (e.g., whether there is a selective response)

Study design

8 The study size is consisting of at least 50 participants (arbitrarily chosen) 31

9. The collection of data is prospectively gathered 8

10. The process of data collection is described (e.g. interview or self-report) 30 Results

11. The results are compared between two groups or more

(e.g., comparison with healthy population and differences in financial toxicity between those with or without work), and/or results are compared between at least two time points (e.g., pre- versus post-treatment)

12. Statistical proof for the main findings is reported 30

13. Relationship between financial toxicity and employment status is described 23 
maximum attainable score ( $\geq 10$ points) were, arbitrarily, considered to be of "high quality." Studies scoring between 50 and $75 \%$ (7-9 points) were rated as "adequate quality." Studies scoring lower than $50 \%$ (i.e., $<7$ points) of the maximum attainable score were considered to be of "low quality."

\section{Results}

\section{Study characteristics}

The search identified 3945 unique citations (PubMed ( $n=$ $2891)$, Web of Science $(n=775)$, CINAHL $(n=180)$, and PsycINFO $(n=99))$ with 31 studies meeting our inclusion criteria (Table 2) [8, 17-43]. All were published between 1990 and 2019 and originated from the USA $(N=16)$, Australia $(N=6)$, the Netherlands $(N=2)$, Canada $(\mathrm{n}=1)$, Japan $(N=1)$, Singapore $(N=1), \operatorname{Iran}(N=1)$, the UK $(N=$ $1)$, Germany $(N=1)$, or Ireland $(N=1)$. A total of 16 studies reported on data from various tumors $[8,18,20,21,26$, 29-33, 36-38, 40, 41, 43], 5 studies focused on breast cancer $[19,25,28,35,42,44]$ and 2 included multiple myeloma patients [22, 45]. The other studies focused on bladder [39], prostate [23], colorectal [24], lung [27], head and neck cancer [34], and bone marrow transplant patients [17]. Time since diagnosis ranged from a mean of 8.4 months before diagnosis [27] until a mean of 13 years after diagnosis [19] often had a broad range, and sometimes was not reported at all. Sample sizes ranged from 129 [19] to 16,771 [30] participants. Eight studies had a longitudinal design $[19,24,25,27,32,35,42$, 44].

Both definitions and measures of financial toxicity varied strongly, and most measures were not validated making comparison between studies difficult. Some studies measured financial toxicity by the presence of consequences of increased costs and decreased income (e.g., bankruptcy, borrowing money, or debt) $[24,29,38,43]$. Others measured financial toxicity by examining OOP costs [16, 21], decreased income $[8,19,20,25-27,31,32,34,36,42,46]$, the COST tool [40, 43, 45], the Goosens' cost diary [19], the Breast Cancer Finances Survey [19], the EORTC QLQ-C30 [18, 28, 33, 34], the Financial Distress/Financial Well-Being scale [21], and by using questionnaires with self-designed questions. Only two studies objectively assessed financial toxicity [27, 42]. Employment status was measured as either unemployment/ceasing working or changes to employment such as a reduction in work hours.

\section{Quality of studies}

The quality of 13 studies included in the review was arbitrarily rated as high, while 16 studies were rated as adequate quality and two as having a low quality (Table 2). The primary limitations of the studies were the lack of information about the degree of selection of the sample (e.g., whether there is a selective response), the cross-sectional research designs, and the lack of a validated financial toxicity measure and/or lack of objectively assessed financial toxicity.

\section{Financial toxicity and employment among cancer survivors versus a normative population}

Four studies were identified that compared employment between those with a cancer diagnosis and those who have not had cancer [8, 20, 24, 37]. The results of 3 cross-sectional American studies showed that, among those $<64$ years of age, being actively treated for cancer decreased the probability of employment [20], and increased employment disability [8], the number of missed workdays per year [8,20,37], the number of days spend in bed [8,37], and the mean annual medical expenditures [8,20,37], compared with those not having cancer. A longitudinal Australian study compared financial strain between cancer survivors and the general population and concluded that although financial strain was higher in survivors compared with controls 6 months after diagnosis, it eased and was comparable with the general population at 12 months post-diagnosis [24].

\section{The relationship between financial toxicity and employment}

The effect of cancer on financial toxicity and employment among cancer survivors was examined in all studies. The quantitative results are summarized in Table 2. Increased financial toxicity was associated with both unemployment, changed or reduced employment, lost days at work, or poor work ability in almost all included studies [8, 18-22, 24-30, $32-34,38,40,42,43,45,46]$. However, a single study from Ireland identified employed individuals at greater risk for financial toxicity since they are more likely to experience a drop in income due to cancer [41]. Measures of financial toxicity varied strongly in these studies.

Examining only those studies that measured the impact of unemployment or ceasing work on financial toxicity identified twelve studies [18, 21, 24, 29, 30, 33, 38, 40, 45-47]. Half of the studies examining the impact of unemployment or ceasing work on financial toxicity have been conducted in the USA [24, 29, 30, 38, 45-47], only two conducted in Australia [23, 24], and one in Germany [18], the Netherlands [33], Iran [21], and Japan [40]. Across cancer types, those who were unemployed or ceased employment experienced greater financial toxicity $[18,21,24,29,33,40,45,46]$, objective financial burden (e.g., large decrease in income, selling/second mortgage on home, withdrawing money from retirement accounts, or bankruptcy) $[29,38,48]$, or expenses [30] than patients who remained employed following their diagnosis. In 


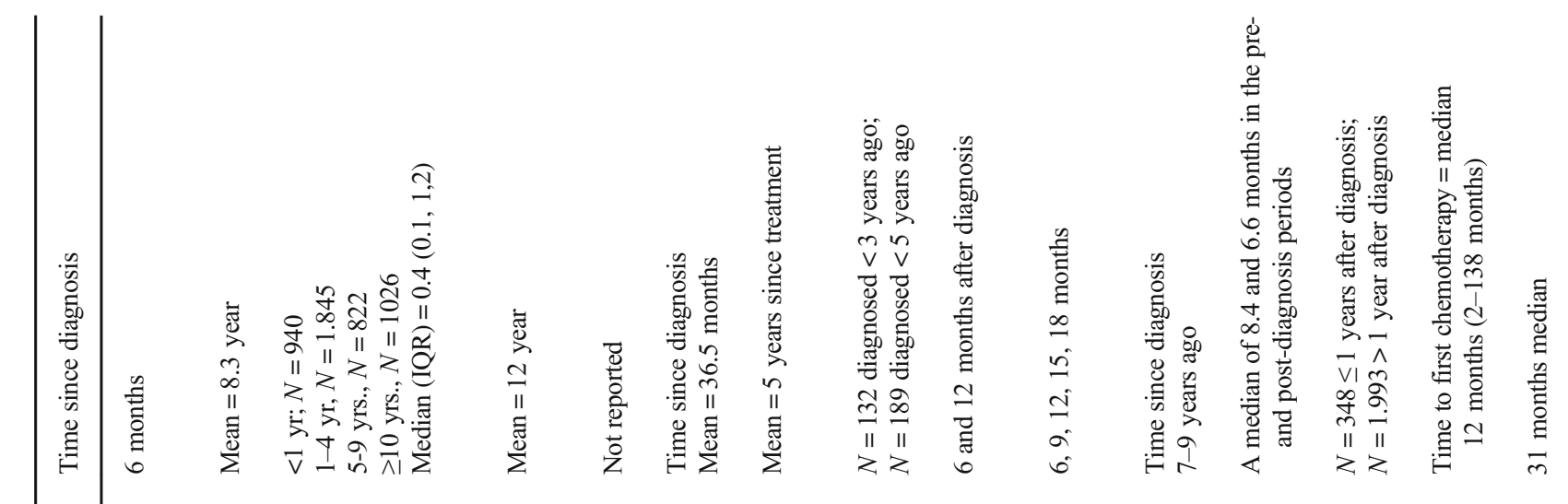

든.

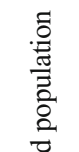

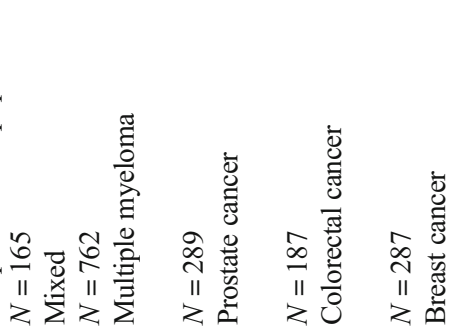

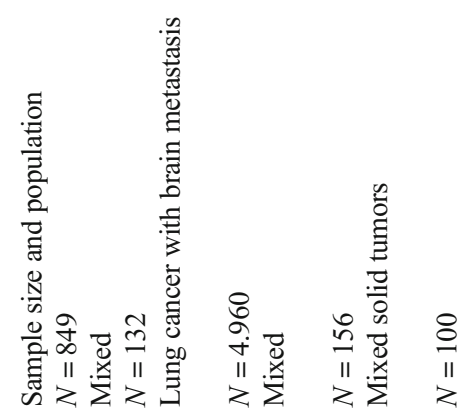

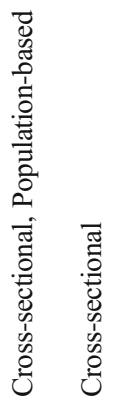
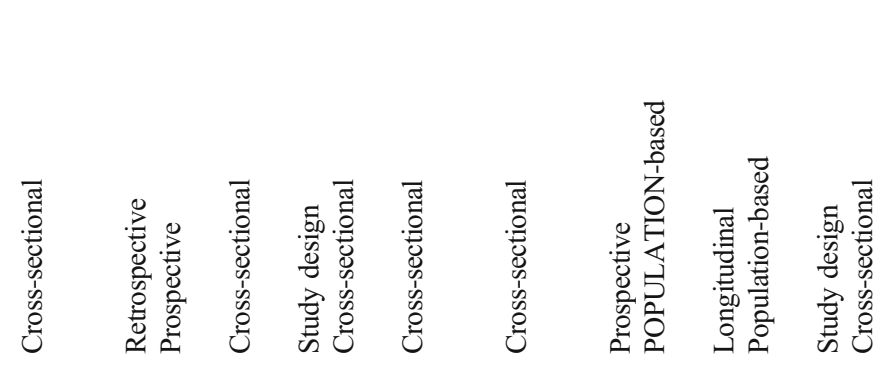

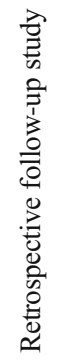

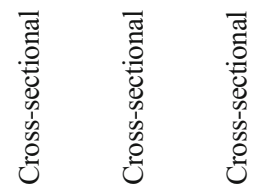

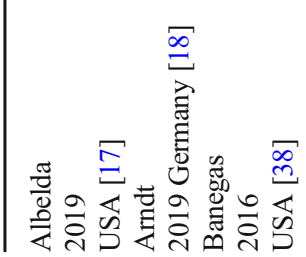

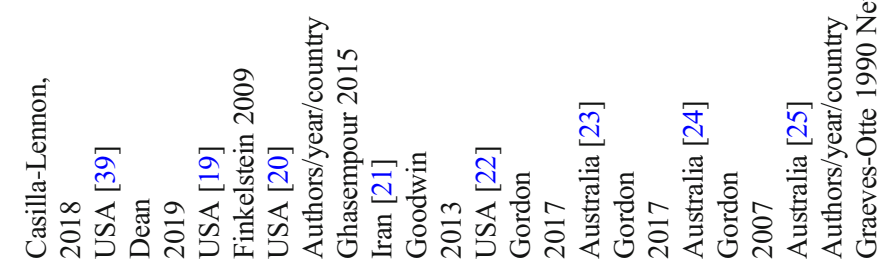

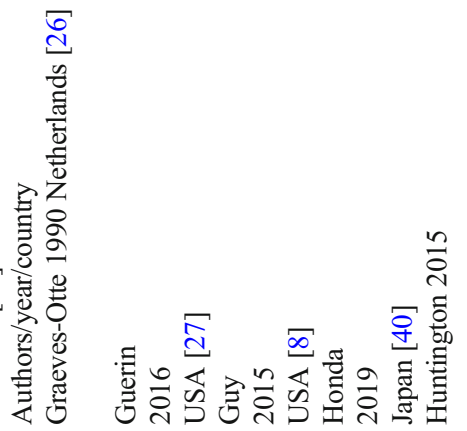




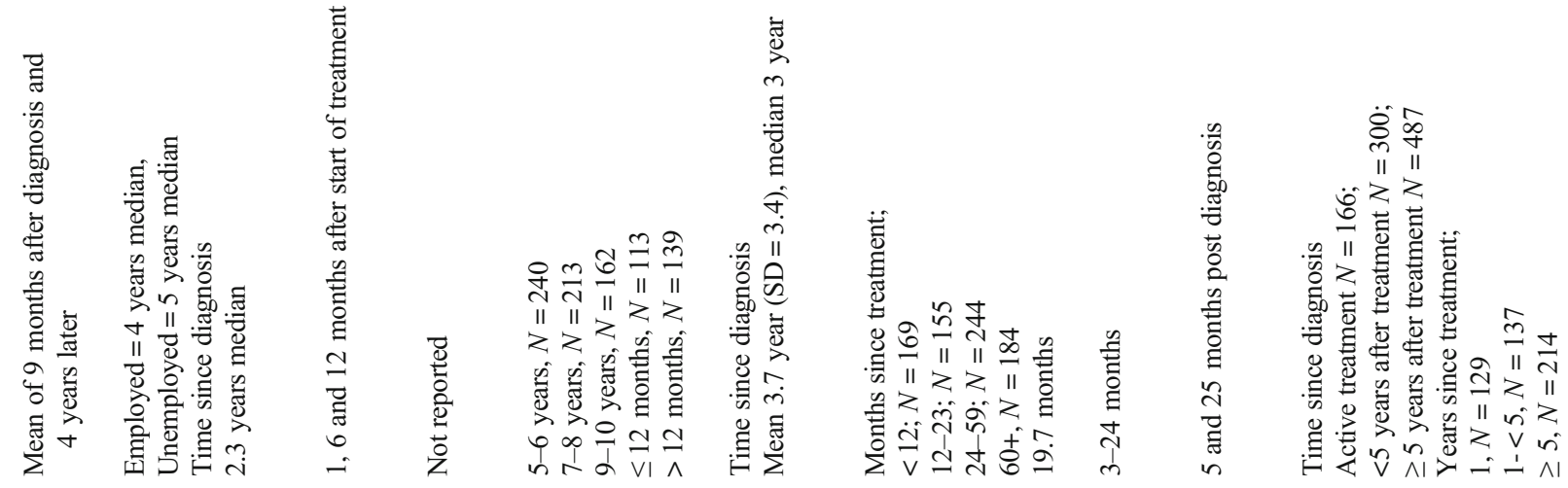

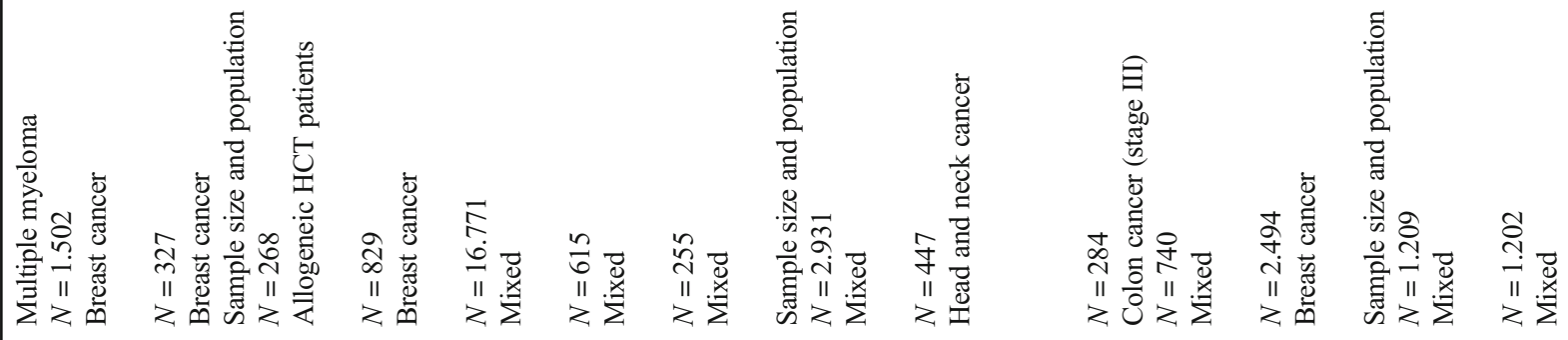

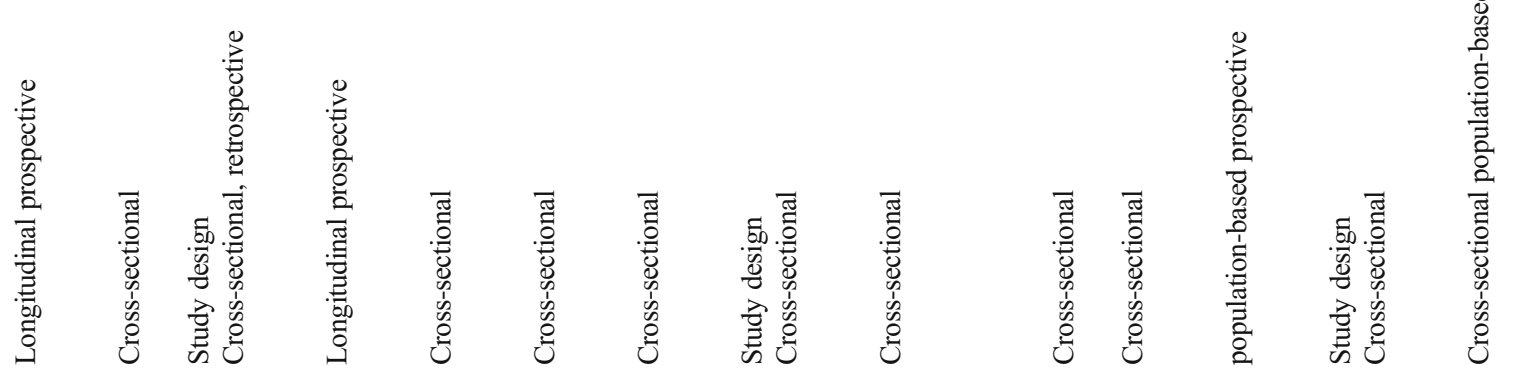

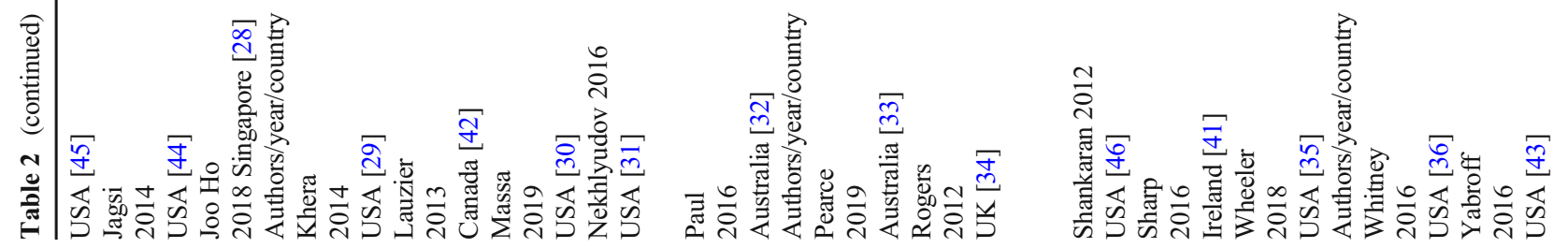




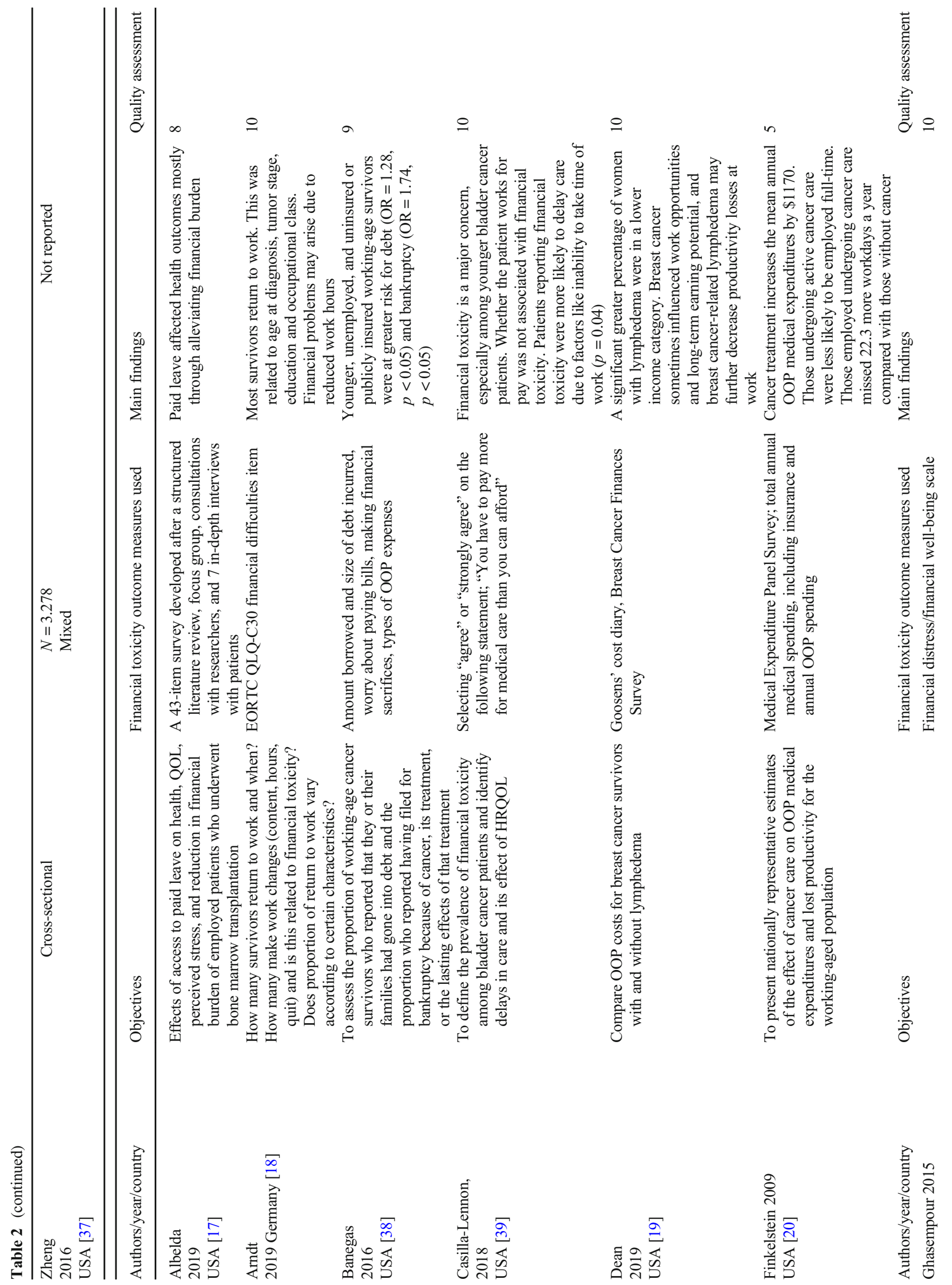




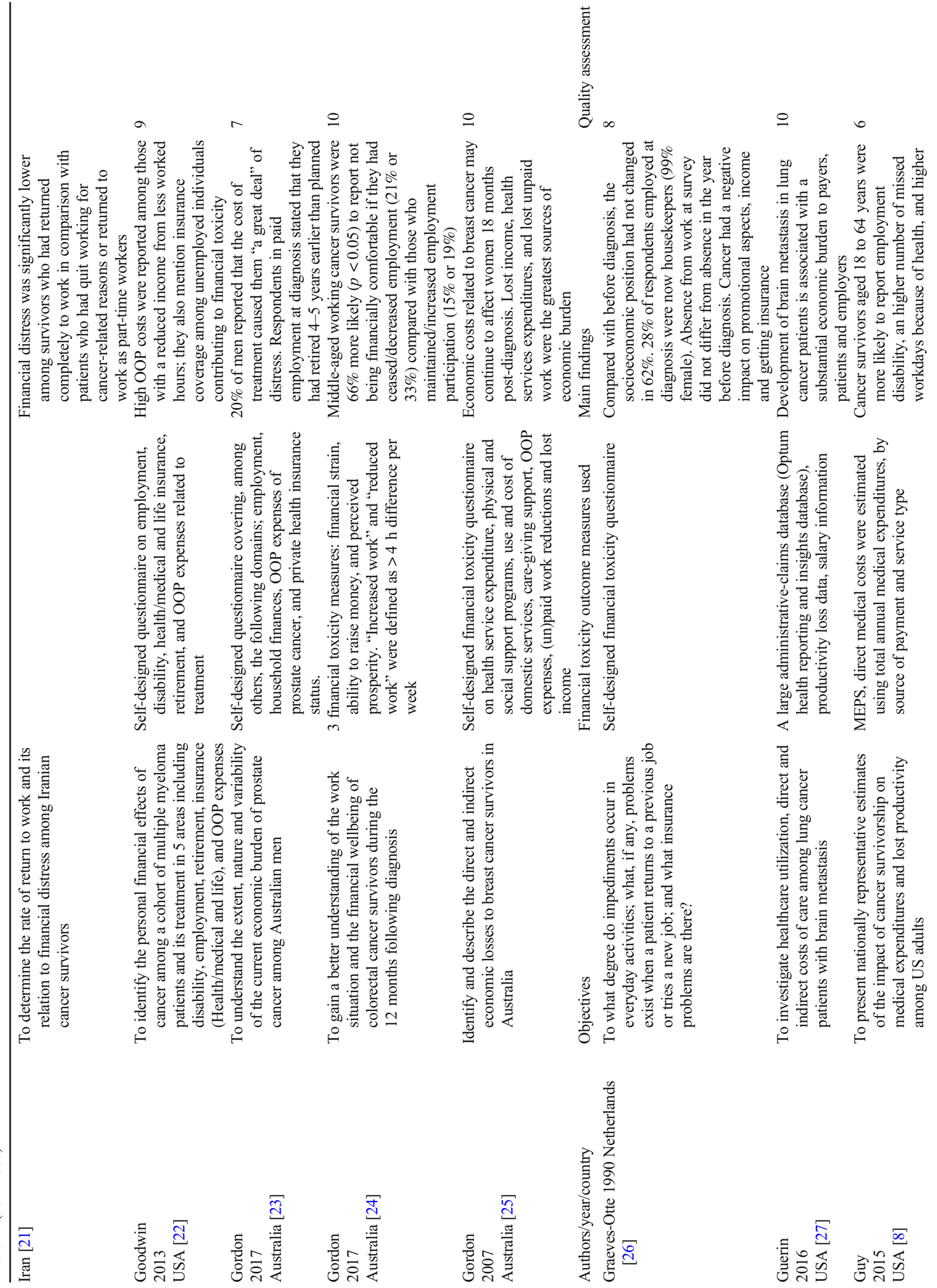




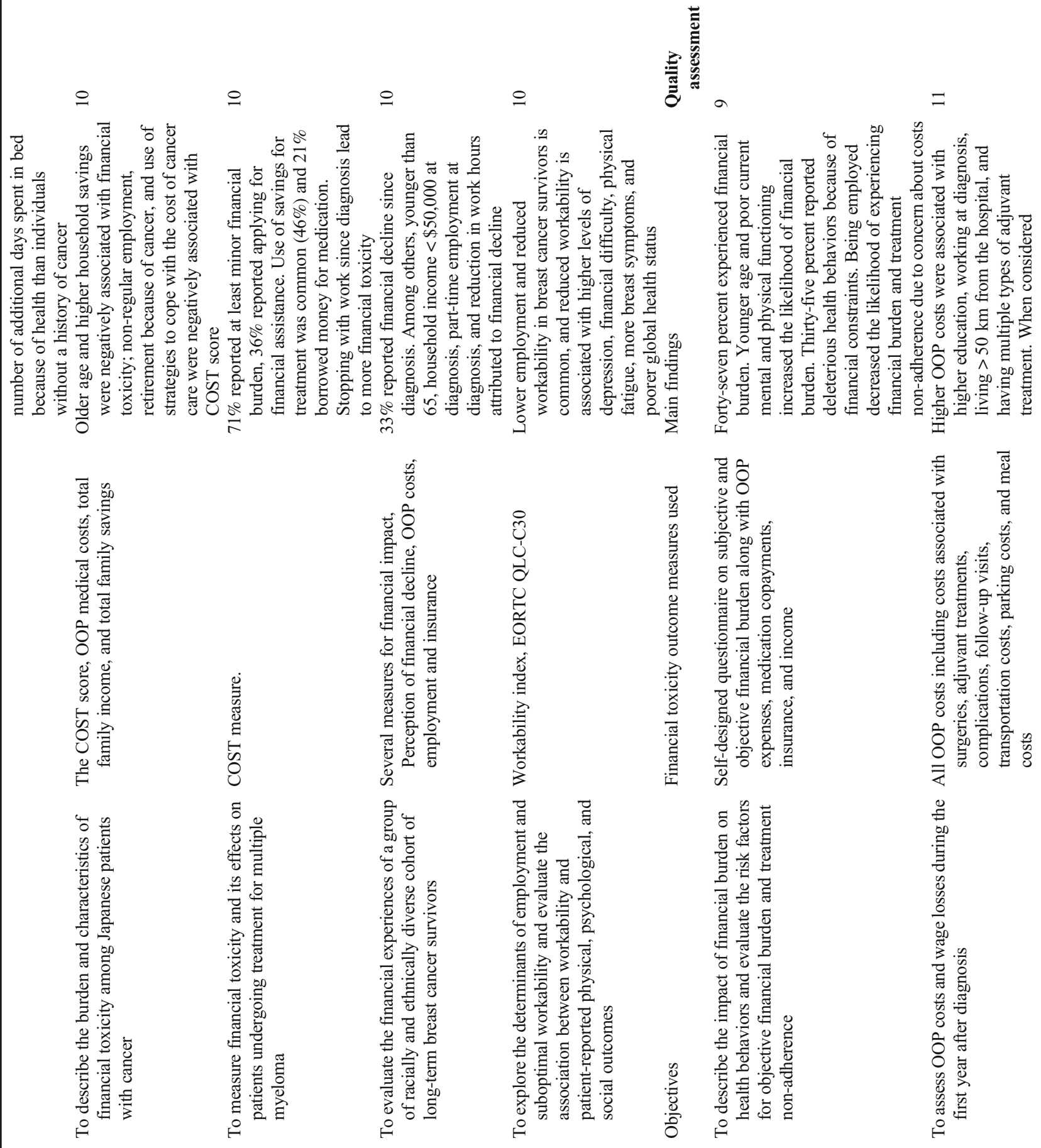

ำ

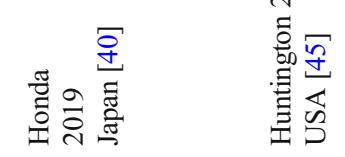

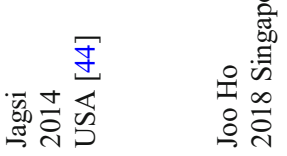

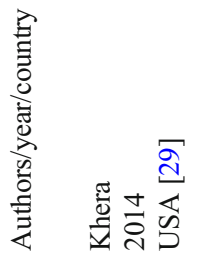

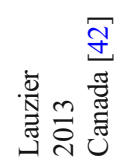




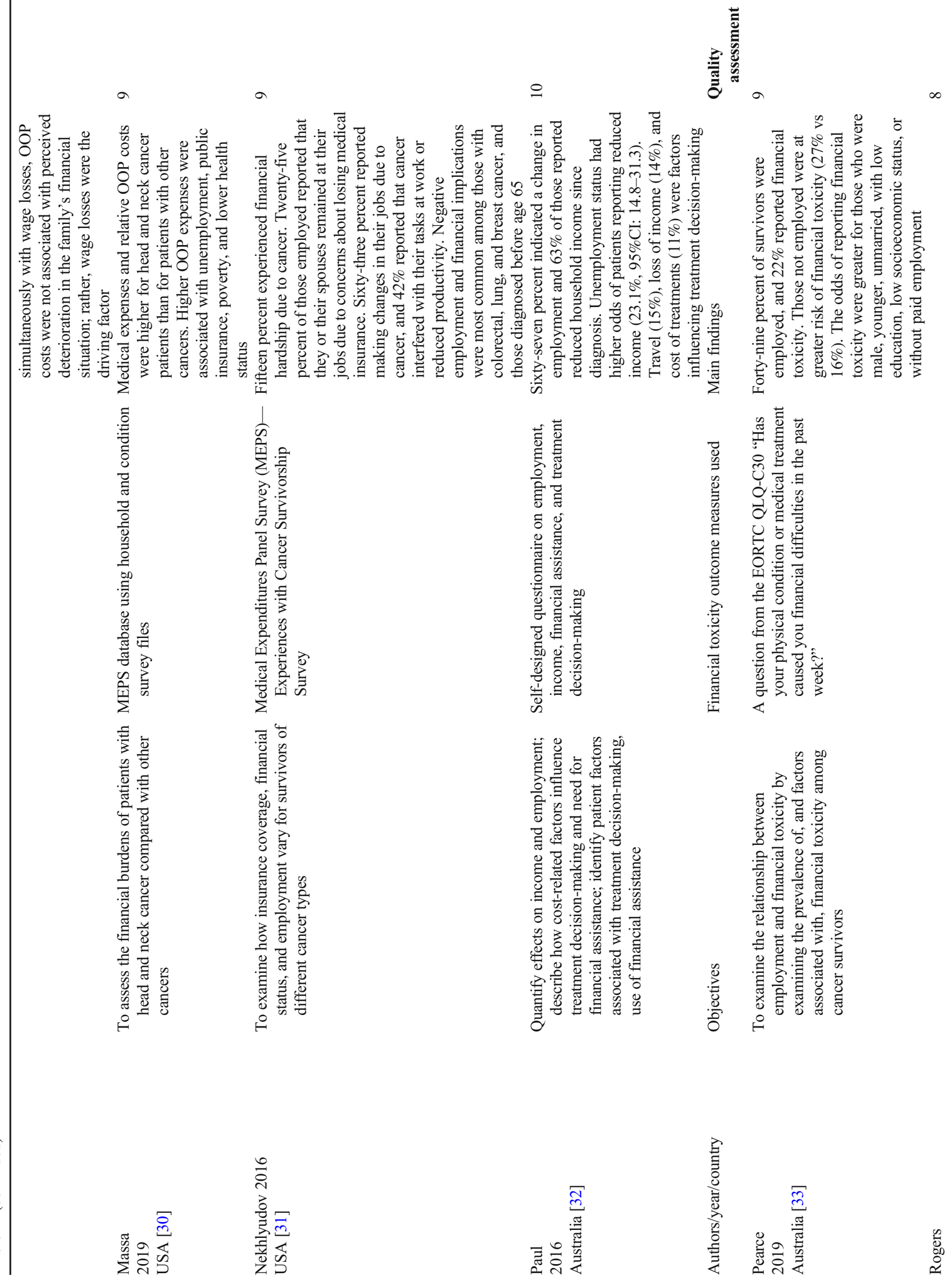




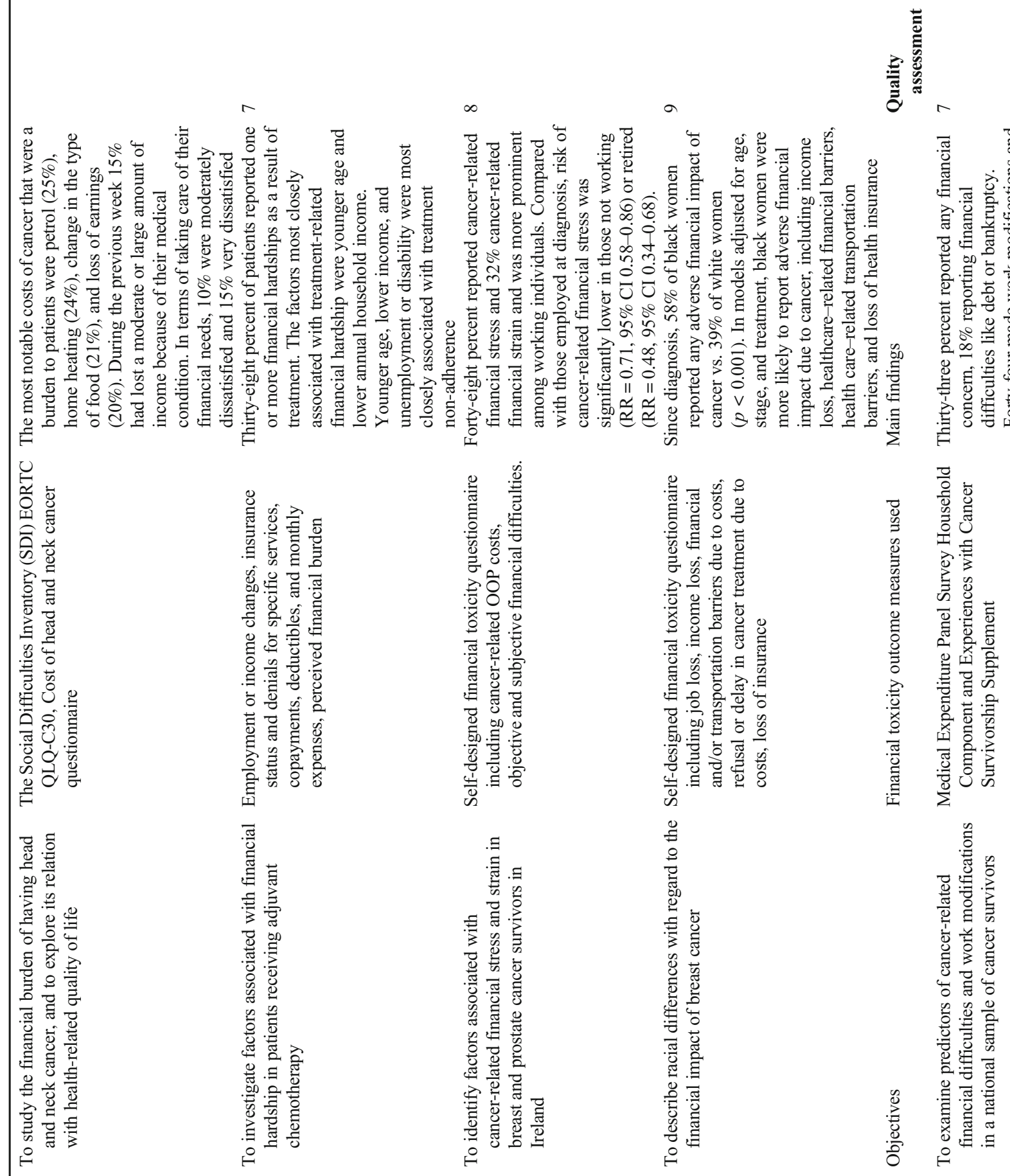

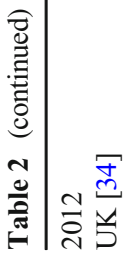

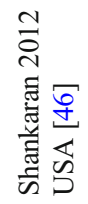

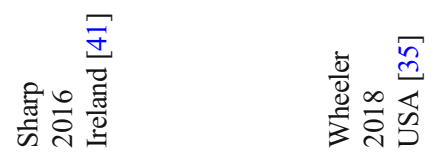

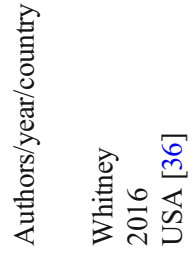




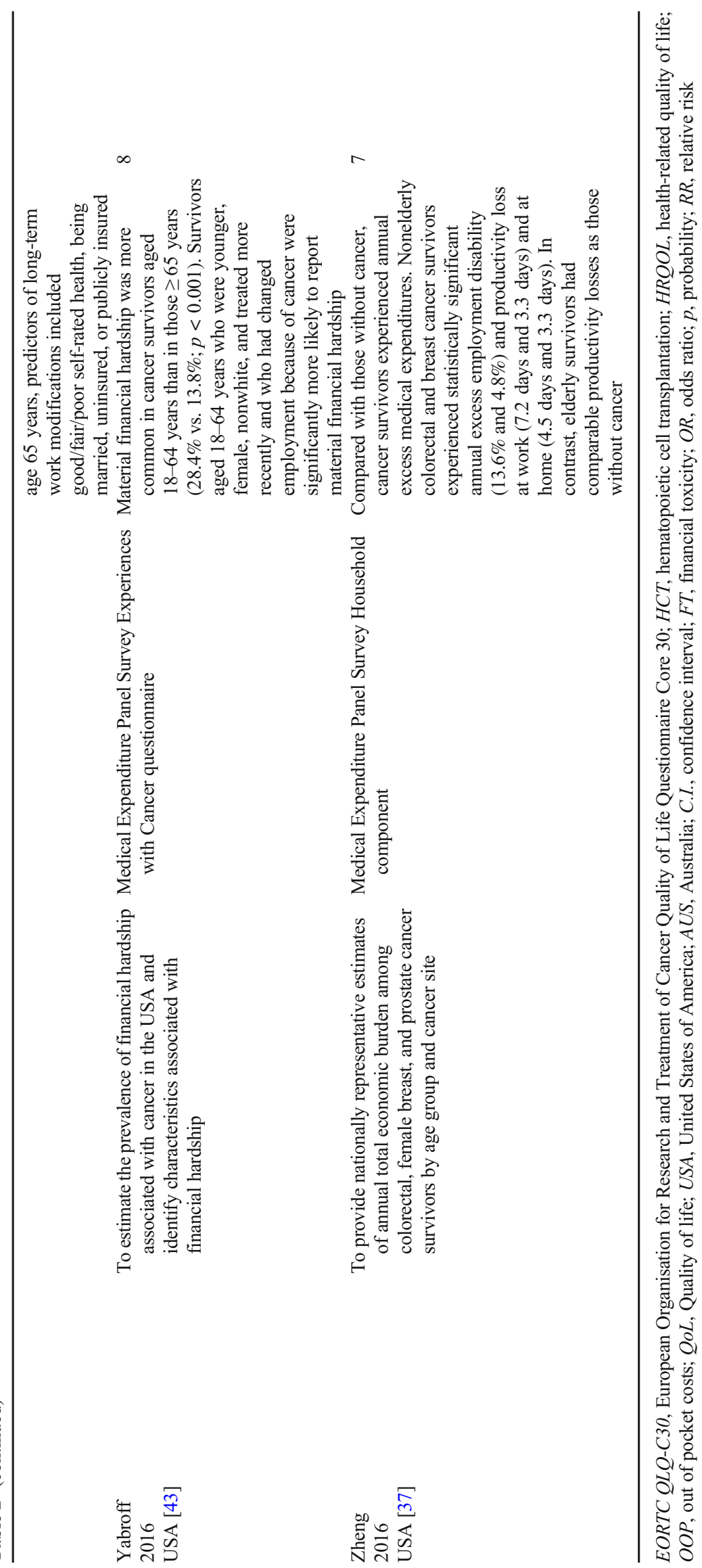


contrast, an Irish study among breast and prostate cancer survivors reported that those who were not working had a significantly lower risk of cancer-related financial stress compared with those working (relative risk $=0.71,95 \%$ CI $0.58-0.86$ ) [41]. A study from the USA including a mixed group of cancer survivors concluded that survivors employed at diagnosis who took extended leave or switched to part-time work were more likely to report financial hardship (49\%) compared with those employed that did not make changes $(20 \%)$ and those who were not employed at diagnosis (17\%) [43]. One study reported that unemployment was significantly associated with financial hardship while retirement was associated with decreased odds of financial hardship [46].

\section{Employment factors associated with financial toxicity}

Studies analyzing employment factors associated with financial toxicity showed that those experiencing less financial toxicity had the following characteristics: paid leave [17], those who returned completely to work [21], not working [41], retired [41], privately insured [41], and those with higher household savings. Also, a higher age at diagnosis [40], being white [36, 43], a longer time since diagnosis $[23,38,43]$, a lower disease stage [35], and a higher educational level $[33,39,40]$ decreased the chance of financial toxicity.

In contrast, those unemployed [29, 33, 38], having to quit a job [18], taking a new job [18], retire [40], or with a reduction in work hours $[18,24,44]$ because of cancer, those with nonregular employment [40], with part-time employment at diagnosis [44], and those with suboptimal workability [28] reported more financial toxicity. For those unemployed, a longer time since diagnosis was associated with a lower risk of financial toxicity but not among those who were employed [33]. Also, individuals reporting higher wage losses who had lower annual income [35, 36, 38, 41, 44-46], a low socioeconomic status [33], public insurance [35, 38, 41], poor insurance coverage [29], lack of substantial prescription drug coverage [44], experienced higher wage losses [42], or were uninsured [35, $38]$ reported more financial toxicity. Moreover, those who were younger [29, 31, 33, 35, 38, 39, 43, 44, 46, 49], being male [33, 41], or female [43], black [35, 39], Spanishspeaking Latinas [44], unmarried [33, 45], had dependents [41], residing in a non-metropolitan service area [36], with a mortgage/personal loan [41], with higher direct OOP costs [41], and increased household bills [41] reported more financial toxicity. Also those having two or more cancer diagnoses [38], a recurrence [44], noninvasive cancer [39], chemotherapy [22, 35, 44], lymphedema [19], lower physical [29, 49], mental [29] and socioemotional functioning limitations [49], and a lower quality of life [33] reported more financial toxicity. No studies analyzed confounders of the association between financial toxicity and employment.

\section{Discussion}

This literature review identified a modest number of studies examining the relationship between financial toxicity and employment indicating relative scarcity of data on this subject. In general, cancer survivors can lose their job, they may have limitations in the amount or kind of work, they can experience job lock (not being able to take promotions or switch jobs) due to concerns of changing healthcare insurance, and they can experience higher cost-sharing when insured (especially in the USA) which can all contribute to financial toxicity. More research in this area is warranted since data varies between countries according to differences in healthcare and health insurance systems.

Unemployment, changed or reduced employment, lost days at work, or poor workability and changes to employment were associated with a higher risk of financial toxicity. However, a single study identified employment as a risk factor for financial toxicity among breast and prostate cancer survivors in Ireland [41]. This finding may reflect differences in health and social care systems [41]. In Ireland, the healthcare system consists of both private and public systems with an income limit determining acceptability for public services [50]. Those that are above the income limit are not accepted for public services and therefore pay for private healthcare. People with private care had higher costs compared with those in the public system, which suggests that employed individuals may be more susceptible to greater healthcare costs and therefore financial strain.

The relationship between negative work changes, and financial toxicity can be partly explained by the link between employment and health insurance. In some countries, like the USA, health insurance is often closely linked with employment. Therefore, losing one's job because of cancer entails losing one's health insurance. These two factors combined are a major risk factor for financial toxicity. However, some studies showed a negative association between work changes and financial toxicity in the setting of the universal healthcare coverage $[24,33]$. This suggests that the association of employment and financial toxicity is not only a function of health care insurance but of social security systems as well. However, health insurance has an important role since those with private health insurance and paid leave often experienced a lower risk of financial toxicity while those with public insurance, those uninsured, those with poor insurance coverage, and those with a lack of substantial prescription drug coverage reported a higher risk of financial toxicity.

Differences between countries in employment and financial toxicity can also be caused by "return to work after cancer" policies. Return to work is influenced by social security systems, especially the length of paid sick leave. Furthermore, differences in legislation, incentives, and possibilities of an employer to provide employees with return to work programs differ among countries.

Besides negative work changes, being younger, non-white, unmarried, of lower education status, and residing with 
dependents or in non-metropolitan service areas were predictive of a higher risk of financial toxicity. Other factors associated with a higher risk of financial toxicity were having lower incomes, low socioeconomic status, a mortgage/personal loans, higher OOP costs and household bills, non-optimal health insurance, lower functioning and quality of life, and being more severely ill or on active treatment. This is not surprising since financial toxicity is a burden often affecting those most disadvantaged. These people often have fewer financial reserves or support on which to draw in times of unexpected financial strain. Also, these factors are often negatively associated with employment as well and therefore may have a compound effect on the likelihood of financial toxicity. Addressing financial toxicity may assist in addressing issues of access to care, equity of care, and may have significant impact on outcomes.

Only four studies compared survivors with a normative population. Three cross-sectional studies from the USA concluded that being actively treated for cancer had serious negative consequences regarding employment and medical expenditure. However, one longitudinal Australian study reported differences in financial strain at 6 months but no differences at 12 months after diagnosis. Time since diagnosis is thus an important is variable to consider but not all studies take this into consideration.

This systematic review has several strengths including a broad search of multiple keywords and search terms across various databases. The quality of most of the studies, as rated by a wellvalidated tool, was moderate to high. There were also a number of limitations to our study, which should be considered. We specifically targeted studies of adult cancer survivors excluding parents, siblings, caregivers, and spouses of cancer survivors. This has restricted the extent to which household financial toxicity can be examined and its relation to employment, although the impacts of financial toxicity are seen to extend to the parents, spouses, and caregivers of survivors [42]. Also, we did not include fully qualitative studies. In addition, we only focused on English language literature. Moreover, most studies were from a selected number of countries which limit generalizability across other countries or healthcare systems. Despite these limitations, this review is the first to explore the relationship between financial toxicity and employment among cancer survivors.

cThis review demonstrates the relative paucity of studies in the area of financial toxicity and employment and highlights a need for further research into the variables that are associated with the relationship between financial toxicity and employment to inform development of interventions to reduce financial toxicity because of employment change. For instance, the variation by cancer type, treatment type(s), duration of treatment(s), healthcare provider, and the role of community, state, and federal policy factors associated with financial hardship are still unclear. Further research should have a longitudinal design in order to focus on how the relationship between financial toxicity and employment changes over time. In addition, the use of a control group is warranted since financial problems can also occur due to other causes then cancer. In addition, the use of a validated financial toxicity measure and the use of a standard definition of financial toxicity will probably lead to results that can be more easily compared between studies.

In clinical practice, healthcare professionals should screen for financial toxicity during the disease trajectory. If financial toxicity is detected, directing patients to financial resources and advocating with an insurance company on behalf of the patient are possible actions one could take. Also, financial toxicity should be discussed with patients after diagnosis and regularly thereafter because it can influence treatment adherence and thus treatment efficacy. This is especially relevant in countries without universal healthcare coverage like the USA. In addition, healthcare professionals should have attention for the value of certain treatments in relation to their costs, and they should be prepared to discuss these tradeoffs with patients. This also implies that healthcare professionals' should be informed on the OOP costs related to treatment. Finally, to decrease financial toxicity, patient should have basic knowledge on health insurance, potential costs of treatment, and available resources as well.

In conclusion, this review shows that financial toxicity is common after a cancer diagnosis but varies strongly between countries since it depends much upon the healthcare system. Researchers, healthcare professionals, health and safety officers in the work place, and patients themselves should all cooperate to tackle these complex issues.

\section{Compliance with ethical standards}

Conflict of interest The authors declare that they have no conflict of interest.

Open Access This article is licensed under a Creative Commons Attribution 4.0 International License, which permits use, sharing, adaptation, distribution and reproduction in any medium or format, as long as you give appropriate credit to the original author(s) and the source, provide a link to the Creative Commons licence, and indicate if changes were made. The images or other third party material in this article are included in the article's Creative Commons licence, unless indicated otherwise in a credit line to the material. If material is not included in the article's Creative Commons licence and your intended use is not permitted by statutory regulation or exceeds the permitted use, you will need to obtain permission directly from the copyright holder. To view a copy of this licence, visit http://creativecommons.org/licenses/by/4.0/.

\section{References}

1. Zafar SY (2016) Financial toxicity of cancer care: It's time to intervene. J Natl Cancer Inst 108(5):djv370. https:/doi.org/10.1093/ jnci/djv370

2. Gordon L, Merollini KM, Lowe A, Chan RJ (2016) A systematic review of financial toxicity among cancer survivors: we can't pay the co-pay. Patient 10:295-309. https://doi.org/10.1007/s40271016-0204-x 
3. Pisu M, Kenzik KM, Oster RA, Drentea P, Ashing KT, Fouad M, Martin MY (2015) Economic hardship of minority and nonminority cancer survivors 1 year after diagnosis: another longterm effect of cancer? Cancer 121(8):1257-1264. https://doi.org/ 10.1002/cncr.29206

4. Zafar SY, Peppercorn JM, Schrag D, Taylor DH, Goetzinger AM, Zhong X, Abernethy AP (2013) The financial toxicity of cancer treatment: a pilot study assessing out-of-pocket expenses and the insured cancer patient's experience. Oncologist 18(4):381-390

5. McNulty J, Khera N (2015) Financial hardship - an unwanted consequence of cancer treatment. Curr Hematol Malign Rep 10(3): 205-212. https://doi.org/10.1007/s1 1899-015-0266-1

6. Ramsey SD, Bansal A, Fedorenko CR, Blough DK, Overstreet KA, Shankaran V, Newcomb P (2016) Financial insolvency as a risk factor for early mortality among patients with Cancer. J Clin Oncol 34(9):980-986. https://doi.org/10.1200/JCO.2015.64.6620

7. Knight TG, Deal AM, Dusetzina SB, Muss HB, Choi SK, Bensen JT, Williams GR (2018) Financial toxicity in adults with cancer: adverse outcomes and noncompliance. J Oncol Pract:JOP1800120. https://doi.org/10.1200/JOP.18.00120

8. Guy GP Jr, Ekwueme DU, Yabroff KR, Dowling EC, Li C, Rodriguez JL, de Moor JS, Virgo KS (2013) Economic burden of cancer survivorship among adults in the United States. J Clin Oncol 31(30):3749-3757. https://doi.org/10.1200/JCO.2013.49.1241

9. Altice CK, Banegas MP, Tucker-Seeley RD, Yabroff KR (2017) Financial hardships experienced by cancer survivors: a systematic review. J Natl Cancer Inst 109(2):1-17. https://doi.org/10.1093/ jnci/djw205

10. Chan RJ, Gordon LG, Tan CJ, Chan A, Bradford NK, Yates P, Agbejule OA, Miaskowski C (2019) Relationships between financial toxicity and symptom burden in cancer survivors: a systematic review. J Pain Symptom Manag 57(3):646-660 e641. https://doi. org/10.1016/j.jpainsymman.2018.12.003

11. Currow D, Aranda S (2016) Financial toxicity in clinical care today: a "menu without prices"1. Med J Aust 204(11):397. https://doi.org/ $10.5694 / \mathrm{mja} 16.00182$

12. Tamminga SJ, de Boer AGEM, Verbeek JHAM, Frings-Dresen MHW (2010) Return-to-work interventions integrated into cancer care: a systematic review. Occup Environ Med 67(9):639-648

13. Mehnert A (2011) Employment and work-related issues in cancer survivors. Crit Rev Oncol Hematol 77(2):109-130. https://doi.org/ 10.1016/j.critrevonc.2010.01.004

14. Liberati A, Altman DG, Tetzlaff J, Mulrow C, Gøtzsche PC, Ioannidis JPA, Clarke M, Devereaux PJ, Kleijnen J, Moher D (2009) The PRISMA statement for reporting systematic reviews and meta-analyses of studies that evaluate health care interventions: explanation and elaboration. PLoS Med 6(7):e1000100. https://doi. org/10.1371/journal.pmed.1000100

15. Mols F, Vingerhoets AJ, Coebergh JW, van de Poll-Franse LV (2005) Quality of life among long-term breast cancer survivors: a systematic review. Eur J Cancer 41(17):2613-2619

16. Beijers AJ, Mols F, Vreugdenhil G (2014) A systematic review on chronic oxaliplatin-induced peripheral neuropathy and the relation with oxaliplatin administration. Support Care Cancer 22(7):19992007. https://doi.org/10.1007/s00520-014-2242-z

17. Albelda R, Wiemers E, Hahn T, Khera N, Salas Coronado DY, Abel GA (2019) Relationship between paid leave, financial burden, and patient-reported outcomes among employed patients who have undergone bone marrow transplantation. Qual Life Res 28(7): 1835-1847. https://doi.org/10.1007/s11136-019-02150-8

18. Arndt V, Koch-Gallenkamp L, Bertram H, Eberle A, Holleczek B, Pritzkuleit R, Waldeyer-Sauerland M, Waldmann A, Zeissig SR, Doege D, Thong MSY, Brenner H (2019) Return to work after cancer. A multi-regional population-based study from Germany. Acta Oncol 58(5):811-818. https://doi.org/10.1080/0284186X. 2018.1557341
19. Dean LT, Moss SL, Ransome Y, Frasso-Jaramillo L, Zhang Y, Visvanathan K, Nicholas LH, Schmitz KH (2019) "it still affects our economic situation": long-term economic burden of breast cancer and lymphedema. Support Care Cancer 27(5):1697-1708. https://doi.org/10.1007/s00520-018-4418-4

20. Finkelstein EA, Tangka FK, Trogdon JG, Sabatino SA, Richardson LC (2009) The personal financial burden of cancer for the workingaged population. Am J Manag Care 15(11):801-806

21. Ghasempour M, Rahmani A, Davoodi A, Sheikhalipour Z, Ziaeei JE, Abri F (2015) Return to work and its relation to financial distress among Iranian cancer survivors. Asian Pac J Cancer Prev 16(6):2257-2261. https://doi.org/10.7314/apjcp.2015.16.6.2257

22. Goodwin JA, Coleman EA, Sullivan E, Easley R, McNatt PK, Chowdhury N, Stewart CB (2013) Personal financial effects of multiple myeloma and its treatment. Cancer Nurs 36(4):301-308. https://doi.org/10.1097/NCC.0b013e3182693522

23. Gordon LG, Walker SM, Mervin MC, Lowe A, Smith DP, Gardiner RA, Chambers SK (2017) Financial toxicity: a potential side effect of prostate cancer treatment among Australian men. Eur J Cancer Care (Engl) 26(1):e12392. https://doi.org/10.1111/ecc. 12392

24. Gordon LG, Beesley VL, Mihala G, Koczwara B, Lynch BM (2017) Reduced employment and financial hardship among middle-aged individuals with colorectal cancer. Eur J Cancer Care (Engl) 26(5). https://doi.org/10.1111/ecc.12744

25. Gordon L, Scuffham P, Hayes S, Newman B (2007) Exploring the economic impact of breast cancers during the 18 months following diagnosis. Psychooncology 16(12):1130-1139. https://doi.org/10. 1002/pon. 1182

26. Greaves-Otte JG, Greaves J, Kruyt PM, van Leeuwen O, van der Wouden JC, van der Does E (1991) Problems at social reintegration of long-term cancer survivors. Eur J Cancer 27(2): 178-181. https://doi.org/10.1016/0277-5379(91)90482-s

27. Guerin A, Sasane M, Dea K, Zhang J, Culver K, Nitulescu R, Wu EQ, Macalalad AR (2016) The economic burden of brain metastasis among lung cancer patients in the United States. J Med Econ 19(5): 526-536. https://doi.org/10.3111/13696998.2016.1138962

28. Ho PJ, Hartman M, Gernaat SAM, Cook AR, Lee SC, Hupkens L, Verkooijen HM (2018) Associations between workability and patient-reported physical, psychological and social outcomes in breast cancer survivors: a cross-sectional study. Support Care Cancer 26(8):2815-2824. https://doi.org/10.1007/s00520-0184132-2

29. Khera N, Chang YH, Hashmi S, Slack J, Beebe T, Roy V, Noel P, Fauble V, Sproat L, Tilburt J, Leis JF, Mikhael J (2014) Financial burden in recipients of allogeneic hematopoietic cell transplantation. Biol Blood Marrow Transplant 20(9):1375-1381. https://doi. org/10.1016/j.bbmt.2014.05.011

30. Massa ST, Osazuwa-Peters N, Adjei Boakye E, Walker RJ, Ward GM (2019) Comparison of the financial burden of survivors of head and neck cancer with other cancer survivors. JAMA Otolaryngol Head Neck Surg 145(3):239-249. https://doi.org/10.1001/jamaoto. 2018.3982

31. Nekhlyudov L, Walker R, Ziebell R, Rabin B, Nutt S, Chubak J (2016) Cancer survivors' experiences with insurance, finances, and employment: results from a multisite study. J Cancer Surviv 10(6): 1104-1111. https://doi.org/10.1007/s11764-016-0554-3

32. Paul C, Boyes A, Hall A, Bisquera A, Miller A, O'Brien L (2016) The impact of cancer diagnosis and treatment on employment, income, treatment decisions and financial assistance and their relationship to socioeconomic and disease factors. Support Care Cancer 24(11):4739-4746. https://doi.org/10.1007/s00520-016-3323-y

33. Pearce A, Tomalin B, Kaambwa B, Horevoorts N, Duijts S, Mols F, van de Poll-Franse L, Koczwara B (2019) Financial toxicity is more than costs of care: the relationship between employment and 
financial toxicity in long-term cancer survivors. J Cancer Surviv 13(1):10-20. https://doi.org/10.1007/s11764-018-0723-7

34. Rogers SN, Harvey-Woodworth CN, Hare J, Leong P, Lowe D (2012) Patients' perception of the financial impact of head and neck cancer and the relationship to health related quality of life. Br J Oral Maxillofac Surg 50(5):410-416. https://doi.org/10.1016/j.bjoms. 2011.07.026

35. Wheeler SB, Spencer JC, Pinheiro LC, Carey LA, Olshan AF, Reeder-Hayes KE (2018) Financial impact of breast cancer in black versus white women. J Clin Oncol 36(17):1695-1701. https://doi. org/10.1200/JCO.2017.77.6310

36. Whitney RL, Bell JF, Reed SC, Lash R, Bold RJ, Kim KK, Davis A, Copenhaver D, Joseph JG (2016) Predictors of financial difficulties and work modifications among cancer survivors in the United States. J Cancer Surviv 10(2):241-250. https://doi.org/10. 1007/s11764-015-0470-y

37. Zheng Z, Yabroff KR, Guy GP Jr, Han X, Li C, Banegas MP, Ekwueme DU, Jemal A (2016) Annual medical expenditure and productivity loss among colorectal, female breast, and prostate cancer survivors in the United States. J Natl Cancer Inst 108(5):djv382. https://doi.org/10.1093/jnci/djv382

38. Banegas MP, Guy GP Jr, de Moor JS, Ekwueme DU, Virgo KS, Kent EE, Nutt S, Zheng Z, Rechis R, Yabroff KR (2016) For working-age cancer survivors, medical debt and bankruptcy create financial hardships. Health Aff (Millwood) 35(1):54-61. https:// doi.org/10.1377/hlthaff.2015.0830

39. Casilla-Lennon MM, Choi SK, Deal AM, Bensen JT, Narang G, Filippou P, McCormick B, Pruthi R, Wallen E, Tan HJ, Woods M, Nielsen M, Smith A (2018) Financial toxicity among patients with bladder cancer: reasons for delay in care and effect on quality of life. J Urol 199(5):1166-1173. https://doi.org/10.1016/j.juro.2017.10. 049

40. Honda K, Gyawali B, Ando M, Kumanishi R, Kato K, Sugiyama K, Mitani S, Masuishi T, Narita Y, Bando H, Taniguchi H, Kadowaki S, Ura T, Muro K (2019) Prospective survey of financial toxicity measured by the comprehensive score for financial toxicity in Japanese patients with cancer. J Glob Oncol 5:1-8. https://doi. org/10.1200/JGO.19.00003

41. Sharp L, Timmons A (2016) Pre-diagnosis employment status and financial circumstances predict cancer-related financial stress and strain among breast and prostate cancer survivors. Support Care Cancer 24(2):699-709. https://doi.org/10.1007/s00520-015-28324

42. Lauzier S, Levesque P, Mondor M, Drolet M, Coyle D, Brisson J, Masse B, Provencher L, Robidoux A, Maunsell E (2013) Out-of- pocket costs in the year after early breast cancer among Canadian women and spouses. J Natl Cancer Inst 105(4):280-292. https://doi. org/10.1093/jnci/djs512

43. Yabroff KR, Dowling EC, Guy GP Jr, Banegas MP, Davidoff A, Han X, Virgo KS, McNeel TS, Chawla N, Blanch-Hartigan D, Kent EE, Li C, Rodriguez JL, de Moor JS, Zheng Z, Jemal A, Ekwueme DU (2016) Financial hardship associated with cancer in the United States: findings from a population-based sample of adult cancer survivors. J Clin Oncol 34(3):259-267. https://doi.org/10.1200/ JCO.2015.62.0468

44. Jagsi R, Pottow JA, Griffith KA, Bradley C, Hamilton AS, Graff J, Katz SJ, Hawley ST (2014) Long-term financial burden of breast cancer: experiences of a diverse cohort of survivors identified through population-based registries. J Clin Oncol 32(12):1269 1276. https://doi.org/10.1200/JCO.2013.53.0956

45. Huntington SF, Weiss BM, Vogl DT, Cohen AD, Garfall AL, Mangan PA, Doshi JA, Stadtmauer EA (2015) Financial toxicity in insured patients with multiple myeloma: a cross-sectional pilot study. Lancet Haematol 2(10):e408-e416. https://doi.org/10.1016/ S2352-3026(15)00151-9

46. Shankaran V, Jolly S, Blough D, Ramsey SD (2012) Risk factors for financial hardship in patients receiving adjuvant chemotherapy for colon cancer: a population-based exploratory analysis. J Clin Oncol 30(14):1608-1614. https://doi.org/10.1200/JCO.2011.37. 9511

47. Guy GP Jr, Yabroff KR, Ekwueme DU, Rim SH, Li R, Richardson LC (2017) Economic burden of chronic conditions among survivors of cancer in the United States. J Clin Oncol 35(18):2053-2061. https://doi.org/10.1200/jco.2016.71.9716

48. Guy GP Jr, Yabroff KR, Ekwueme DU, Virgo KS, Han X, Banegas MP, Soni A, Zheng Z, Chawla N, Geiger AM (2015) Healthcare expenditure burden among non-elderly cancer survivors, 20082012. Am J Prev Med 49(6 Suppl 5):S489-S497. https://doi.org/ 10.1016/j.amepre.2015.09.002

49. Rogers SN, Harvey-Woodworth CN, Lowe D (2012) Patients' perspective of financial benefits following head and neck cancer in Merseyside and Cheshire. Br J Oral Maxillofac Surg 50(5):404 409. https://doi.org/10.1016/j.bjoms.2011.07.020

50. van Doorslaer E, Wagstaff A (1992) Equity in the delivery of health care: some international comparisons. J Health Econ 11(4):389 411. https://doi.org/10.1016/0167-6296(92)90013-Q

Publisher's note Springer Nature remains neutral with regard to jurisdictional claims in published maps and institutional affiliations. 